\title{
Public Administration Practitioners at Academic Conferences: Why to Present and How to Succeed
}

\author{
David S. Reed \\ David.Reed@PubAdmin.org
}

\section{Why to Attend and Present}

Most practitioners never attend any of the public administration academic conferences, but it could be well worth your time. And if you attend, it makes sense to give a presentation. I base this advice on experience presenting at three conferences, organizing panels for two, being rejected by one, and attending a couple more.

The highest profile conferences are the national gatherings of the American Society for Public Administration (ASPA) and the Association for Public Policy Analysis and Management (APPAM), but there are many more. A partial list is at https://pagateway.newark.rutgers.edu/conf2016 The smaller events organized by regional associations, local chapters or topic-specific sections are a way to start without investing the time, travel and registration fees of national conferences. Public administration conferences are job markets for professors and other PhDs, but there are also benefits for practitioners, whose career track is separate from the academics these conferences are designed for.

The ostensible reason for attending is to learn from the presentations, and this can be a real benefit. The findings and analytic techniques that academics present at conferences are outside what practitioners are likely to be exposed to in our day-to-day jobs.

But often a bigger benefit is building professional relationships. Many people practicing public administration were educated in a different field, so a conference can be an introduction to the public administration professional community. Few of the people you meet at an academic conference will be fellow practitioners, but those few tend to be the most innovative practitioners, the best prospects for collaboration within and outside your job, and the most willing to share information. As for the academics at the conference, if they think you can steer grants or contracts their way then you will be the belle of the ball. Otherwise, it can be hard to find common ground with academics at the conference. It helps if you are presenting, because it raises your profile and gives you a natural topic of conversation.

There are additional reasons why, if you are investing the time and money to attend a conference, it makes sense to be a presenter:

- Sharpen your thinking. Practitioners' presentations at work are often judged on whether they justify a predetermined position. The prospect of presenting your ideas to an audience that 
includes diverse points of view, and at its best will be knowledgeable and analytic, can encourage you to think through your points more rigorously.

- Get information and contacts. In the question period after your presentation, and in hallway conversations, you may get useful suggestions for research papers you should read, or people you should contact, to advance your work in your presentation topic.

- Strengthen your resume. Presenting at a conference is evidence of your expertise. This is especially useful if your job does not provide much opportunity for accomplishments that are recognized outside your organization. Aside from creating a good impression on your resume, conference presentations sometimes count as qualifications. For example, the U.S. Government's qualification standards for policy and administrative analysis positions say, "Consideration should be given for active involvement in [public policy and] public administration organizations, presentation of papers, and participation in seminars." (U.S. Office of Personnel Management 2016)

- Being a presenter may help persuade your employer to pay your expenses for attending the conference, or at least let you attend on paid time. But using your employer's resources may lead them to claim a right to control the content of your presentation, so it isn't practical in all cases.

- And the altruistic reason - present to advance the art of public administration. As we discuss in the next section, your experience with what you have tried, what worked and what failed in your practice of public administration can be valuable to practitioners and academics, and it is a kind of knowledge that is in short supply at conferences.

\section{What to Present}

Most public administration conferences advertise that they welcome practitioners, but the organizers might not have much idea of what a practitioner presentation should be. Presentations by academics generally follow a pattern: The presenter has created or accessed some body of data--survey research, administrative records, interviews, etc.--and applies statistical techniques or qualitative analysis to find patterns in the data that relate to a topic in public administration theory. A practitioner could use this same approach, but a different approach may be more valuable.

A practitioner can present her own experience with techniques she has applied or cases she has participated in. A frank presentation of what she tried, what worked, what failed and what she observed can show other practitioners what they want to copy or avoid, and can show academics a specific instance of phenomena they might want to study more generally. As examples, here are some practitioner presentations from the Northeast Conference on Public Administration (NECoPA) that I helped organize: 
- A Federal employee described the intrapreneurial approach she and two colleagues used to create a series of safe spaces for conversation on diversity and inclusion in their agency, on their own initiative. Management support came after they had implemented their model as a fact on the ground. (Watson 2015)

- An Internet developer started a project to create the first searchable database of Inspector General reports across Federal agencies. His conference presentation explained "scraping" techniques for harvesting information from web sites, and discussed issues of leading an open-source development effort as a government employee's off-duty side project. (Mill 2014; Mill 2015)

- A government worker presented the "annotated work instruction" technique he developed to achieve some of the benefits of documented work processes, even when an agency's management is unwilling to promulgate implementable procedures. (Reed 2015)

There are two common problems I have noticed in helping practitioners develop their conference presentations. The first is promoting something, rather than presenting observation and analysis. Any of us may be enthusiastic about a policy position, a technique or some other idea. We may be proud of an accomplishment we were part of. We may know that it would help our career to describe our accomplishments in the most favorable way, or to put our employer in the most favorable light. But these run counter to what should be the purpose of a presentation at a professional conference, which is to share information with one's colleagues that will increase our understanding and improve our practice. If your audience at the conference is good, then they will be alert to whether you are trying to be objective or self-serving. They will look for whether you discuss both the advantages and limitations of your technique, what your project achieved and what problems you encountered, which results seem reproducible and which may be flukes.

The second problem is lack of an original contribution to knowledge in the field. What we get used to producing in school is along the lines of a book report-present information from several secondary sources to demonstrate that we have done background research on a topic. What we see in the media, especially social media, are brief recapitulations of somebody else's book or speech. But a presentation at a professional conference should be judged by whether it adds to the knowledge of people who are already working on the topic. Your new information does not need to be broad in scope to be valid and valuable. If you applied a management technique or an analytic technique in your job, then your observations on how you did it and how it worked out can be valuable. If you modified a technique, then your experience with your modifications can inform your colleagues' practice. If you encountered an unusual situation at work, then you may want to present along the lines of a medical journal case report-describing the situation you encountered, what you did in response, and how it worked out. ${ }^{1}$ The key question in preparing a

\footnotetext{
${ }^{1}$ Medical journal case reports are different from the case studies used in teaching public administration. See (Agha and Rosin 2010; Cohen 2006; Pulec 2001).
} 
conference presentation should be, "What information am I adding to what people working in this field already know?"

\section{How to Present}

The usual session at a public administration conference is a panel of three or four presenters, plus a moderator. Each presenter is allotted 15 or 20 minutes, with time at the end for audience questions. The conference will issue a call for proposals a few months in advance, inviting proposals for complete panels and for individual presentations. Conference organizers have a limited number of rooms and times, and they want to maintain quality, so they will pick and choose among proposals. But most conferences accept most of the proposals they receive. If you send a proposal for an individual presentation, and it is accepted, then the conference organizers will choose a panel to include your presentation.

There will be several panels running concurrently in different rooms, and each person attending the conference chooses which she will go to. So attendance at a panel can vary from packed to embarrassingly sparse. At one panel, I was the only audience that showed up - it was just the presenters and me. As a practitioner, your name and your topic will probably be unfamiliar to most people at the conference. So after your proposal is accepted and your panel is scheduled, you should do outreach to encourage people attending the conference to come to your panel. If you know anybody who will be at the conference, then contact them personally to invite them to attend your panel. If somebody on another panel is speaking on a topic related to yours, then contact them to say you are looking forward to attending their panel and suggest that they attend yours.

Coordinate in advance with your panel moderator about how she wants your slides. Should you email them to her in advance, or have them on a USB drive, or should you have your own computer to plug into their projector? What file format do they need (PowerPoint, PDF, etc.)? Surprisingly, many public administration conferences still don't provide WiFi in the session rooms, so don't depend on going online during your panel.

\section{Conclusion}

For a practitioner, attending and presenting at a public administration conference is an opportunity to learn, to sharpen your thinking by preparing for a knowledgeable audience, to build professional relationships, strengthen your resume, and contribute to advancing the art of public administration.

\section{References}

Agha, Riaz, and R. David Rosin. 2010. "Time for a New Approach to Case Reports." International Journal of Surgery Case Reports 1 (1): 1-3. doi:10.1016/j.ijscr.2010.04.001. 
Cohen, H. 2006. "How to Write a Patient Case Report." American Journal of Health-System Pharmacy 63 (19): 1888-92. doi:10.2146/ajhp060182.

Mill, Eric. 2014. "Opening up Government Reports through Teamwork and Open Data." OpenGov Voices. November 7. http://sunlightfoundation.com/blog/2014/11/07/opengovvoices-opening-up-government-reports-through-teamwork-and-open-data/.

- 2015. "Inspecting the Inspectors General: With Computers." presented at the Northeast Conference on Public Administration (NECoPA), Arlington, VA, November 6. http://pubadmin.org/necopa-15-eric-mill-inspecting-the-inspectors-general/.

Pulec, Jack L. 2001. “The Value of the Case Report - Brief Article.” Ear, Nose \& Throat Journal, January. http://search.proquest.com/openview/aa8d448abe21b972b3ac1f79e4ca59b9/1?pqorigsite $=$ gscholar.

Reed, David S. 2015. "Annotated Work Instructions: An ISO 9000 Hack." presented at the Northeast Conference on Public Administration, Arlington, VA, November 6. https://drive.google.com/file/d/0B0fUKRnu1oAhMlE3Qmc5dVhfOTA/view?usp=sharin g\&usp=embed_facebook.

U.S. Office of Personnel Management. 2016. "General Schedule Qualification Standards: Policy Analysis Positions.” Accessed February 7. http://www.opm.gov/policy-dataoversight/classification-qualifications/general-schedule-qualification-standards/specialtyareas/policy-analysis-positions/.

Watson, Amber. 2015. "Forest Service Diversity \& Inclusion Coalition for Empowerment (DICE)." MyUSDA, August. http://www.dm.usda.gov/docs/news/MyUSDA\%20August\%202015.pdf. 